\title{
Level of knowledge, attitude, and practice of family planning and associated factors among disabled persons, north-shewa zone, Amhara regional state, Ethiopia
}

Alemayehu Gonie Mekonnen ${ }^{1 *}$ D, Alebachew Demelash Bayleyegn ${ }^{1}$, Yared Asmare Aynalem', Tigist Demssew Adane', Mikyas Arega Muluneh² and Meaza Asefa ${ }^{3}$

\begin{abstract}
Background: In Ethiopia, people with disabilities face socioeconomic disadvantages and they have a limited access to sexual and reproductive health information including family planning service. At present, however, there is a scarcity of research on the association between disability and family planning, and only limited data is available for disabled people in Ethiopia. Hence, this study assessed the level of knowledge, attitude, and practice of family planning and associated factors among disabled persons in North-shewa zone, Amhara regional state, Ethiopia.

Methods: A cross-sectional survey was conducted from June to October 2019. A total of 397 study participants were interviewed using a structured and pre-tested questionnaire. A multistage systematic sampling technique was employed to select study participants. Data were entered into Epi data and exported into Statistical Package for the Social Sciences (SPSS) version 21 for analysis. Logistic regression was performed to analyze the data. A significant association was declared at a $p$-value of less than 0.05 .

Results: Forty-six percent of study participants were knowledgeable about family planning methods. The injectable was the most known method of modern contraception (74.8\%) while withdrawal (18.1\%) was the least known traditional family planning method. Fifty-five percent of our study participants had a good attitude about family planning methods and one-fourth (24.5\%) of disabled persons currently utilized any method of family planning. Those having a good knowledge of family planning were 1.6 times more likely to utilize family planning methods than those having poor knowledge of family planning methods ( $A O R=1.61, \mathrm{Cl}=1.27,16.24)$. Moreover, participants who completed college education were 7 times more likely to have a good knowledge of family planning methods than uneducated participants ( $\mathrm{AOR}=7.23 ; 95 \% \mathrm{Cl}=2.28,22.06$ ).
\end{abstract}

Conclusions: In this study, the knowledge, attitude, and practice of disabled people about family planning methods were relatively low. Due attention should be given to ensure that disabled people are well informed about family planning methods through information, education, and communication activities.

Keywords: Family Planning, Contraceptive, Disability, Debre Berhan

*Correspondence: alemayehugonie19@gmail.com

'Department of Nursing, College of Health Science, Debre Berhan University,

Po. Box 445, Debre Berhan, Ethiopia

Full list of author information is available at the end of the article

(c) The Author(s). 2020 Open Access This article is licensed under a Creative Commons Attribution 4.0 International License, which permits use, sharing, adaptation, distribution and reproduction in any medium or format, as long as you give appropriate credit to the original author(s) and the source, provide a link to the Creative Commons licence, and indicate if changes were made. The images or other third party material in this article are included in the article's Creative Commons licence, unless indicated otherwise in a credit line to the material. If material is not included in the article's Creative Commons licence and your intended use is not permitted by statutory regulation or exceeds the permitted use, you will need to obtain permission directly from the copyright holder. To view a copy of this licence, visit http://creativecommons.org/licenses/by/4.0/ The Creative Commons Public Domain Dedication waiver (http://creativecommons.org/publicdomain/zero/1.0/) applies to the data made available in this article, unless otherwise stated in a credit line to the data. 


\section{Introduction}

Family planning (FP) is an effective way of controlling fertility within a human rights framework by giving couples the ability to have their desired family size $[1,2]$. Family planning has a significant role in improving the health of the mother and the child by avoiding undesired pregnancies and abortions, thus reducing the maternal and child mortality rate [3, 4]. However, social inequality, religious/cultural barriers, weak coordination across sectors, inadequate quality assurance actions, and misconceptions about modern contraceptives were reported as the challenges for family planning implementation [1, 5-7].

Specifically, persons with disabilities are marginalized groups of the populations and they frequently marginalized from FP education due to misconceptions that they are not sexually active [8-10]. Furthermore, disabled people may be subjected to unsafe abortion due to longstanding stigmatization [11]. They have poorer health outcomes than non-disabled people as a result of less access to reproductive health information. Healthcare services also lack sign language interpreters and other information formats such as Braille, audio, or plain language which can provide advice on sexual health-related issues including FP methods [12]. Remarkably, they were often unable to access community meetings about FP services [13]. Moreover, their disabilities may limit their chances to interact with non-disabled peers that can be the best opportunity for informal learning about sexual health and family planning [14].

Although disabled people have the same reproductive health needs as the abled people and they want to space and limit the number of children to their economic capacity [15], they are notably absent from equitable reproductive health access [16] and face barriers to information [17]. Health facilities lack physical infrastructure, suitable and affordable transportation, and assistive devices for persons with disabilities [11, 18]. As such, disabled people face unique barriers to accessing family planning services and are often treated as a low priority for those services. They are often socially isolated and abused which creates obstacles to obtaining FP services [12]. Stigma and negative attitudes by healthcare providers towards disabilities have been commonly cited as the barriers to access and uptake of family planning for disabled people $[11,19]$. The previous study also reported a variety of factors that affect access to and uptake of family planning among people with disabilities. For example, research from four African countries found a lack of knowledge about FP methods and fear of sideeffects are issues affecting access to and uptake of family planning among people with disabilities [20].

In Ethiopia, people with disabilities face socioeconomic disadvantages and they have a limited access to sexual and reproductive health information including family planning services. They have an increased risk of SRHrelated problems and have become the main focus in recent years. At present, however, there is a scarcity of research on the association between disability and family planning, and only limited data is available for disabled people in Ethiopia. Hence, this study assessed the level of knowledge, attitude, and practice of family planning and associated factors among disabled persons in Northshewa zone, Amhara regional state, Ethiopia. An examination of the knowledge and attitude towards FP and the factors which influence their attitude will guide the effective usage of FP services for disabled people who are marginalized groups of the populations.

\section{Methods and materials}

Study design, setting and period

A cross-sectional survey was conducted from June to October 2019 in the North-shewa zone, Amhara regional state, Ethiopia. The Debre Berhan town (the zone city) is located at 130-k meter far from Addis Ababa (the capital city of Ethiopia). An estimated 214,595 people with any form of disability are estimated to live in the North-shewa zone. The zone has 10 functional disability-support organizations: one is found in Debre Berhan town and nine are found in the other nine districts of the zone. The rest 15 districts have no functional disability support-organization. Overall, these disability-support organizations comprised a total number of 1500 disabled persons. These organizations support all disabled peoples (physically handicapped, hearing impairment, partial mental impairment, visual impairment, multiple impairments). The support organizations provide advocacy service, provide life skill training and support to live in the community, get involved in work (unpublished zonal health department report, 2019).

\section{Study population}

All the reproductive-age groups of disabled people who enrolled in the disability-support organizations in the north-shewa zone were the study participants. Those who were ill and unable to communicate due to being ill were excluded from the study. Dual disabilities such as unable to see plus unable to hear were also excluded from the study.

\section{Sample size and sampling technique}

The sample size was calculated using a single population proportion formula. The assumptions were: the proportion of disabled persons who had reproductive health knowledge as $79.6 \%(p=0.796)$ taken from Tanzania [16], with 95\% confidence interval (CI) to be 1.96, and margin of error to be $5 \%$. Adding a non-response rate of 
$5 \%$ and the design effect of 1.5, a total sample size of 412 persons with disabilities were selected.

A multistage systematic random sampling technique was employed. In the first sampling unit, five disabilitysupport organizations were selected randomly. In the second sampling unit, the lists of disabled people (registry) were used as the sampling frame. The registry contained the contact addresses of disabled people. The calculated sample size was proportionally allocated to disability-support organizations and the required numbers of participants were selected using a systematic random sampling technique.

\section{Data collection}

A pre-tested and structured questionnaire was used to collect the data. The questionnaire was designed in English then translated into Amharic (native language) and back into English to ensure consistency. The data were collected by trained enumerators through a faceto-face interview. Five data collectors and five supervisors participated in the study. One of the data collector was a certified sign language interpreter who could collect data from participants who have a hearing impairment. Data completeness were checked by the investigators and supervisors.

\section{Measurements}

Most of the questions were taken from the Ethiopian demographic health survey 2016 [21] and peer-reviewed literature $[14,22]$. The questions comprise the following sections; socio-demographic characteristics and questions which examined the participant's knowledge, attitude, and practice of FP methods. Knowledge questions were: what is family planning? Which FP methods did you know? What are the side effects of using family planning? Respondents answered either "Yes" or "No" or "Do not know" from the listed options. The attitude of respondents towards FP methods was assessed with seven attitudinal questions. All attitudinal statements were stated positively. The participants could choose one of the three possible response categories ( $1=$ yes (agree), $2=$ no (disagree), $3=$ do not know). The practice of the FP was assessed with two statements: do you currently utilize any of the FP methods? Which type of FP methods do you utilize?

Mean scores of knowledge and attitude about FP were calculated to classify the respondents into two groups (knowledgeable and not knowledgeable, good attitude and poor attitude). To calculate the mean score of knowledge, participants who answered "Yes" were considered as correctly answered and those who answered "No" and "I do not know" were considered as not answered correctly. Respondents who scored the mean and above the mean score of the correctly answered questions were classified as knowledgeable, less than the mean score of correct answers were classified as not knowledgeable. To calculate the mean score of attitude, participants who answered "yes/agree" were considered as correctly answered and those who answered "no/disagree" and "I do not know" were considered as not answered correctly. Respondents who scored the mean and above the mean score of attitudinal statements were considered as having a good attitude and less than the mean score as a poor attitude. Concerning family planning practice, it was measured by calculating the percentage of disabled people who currently utilized any of family planning methods. If a married man whose wife was using FP of her choice and he could report that her FP utilization, then he was considered as the current FP user.

\section{Data processing and analysis}

Data was checked for completeness and inconsistencies. Epi-data version 3.1 was used for data entry and data were exported to SPSS version 21. Descriptive statistics were computed. Logistic regression was performed to analyze the data. The bivariate logistic regression analyses were performed between independent and the outcome variables. Those independent variables which were statistically significant in the bivariate model ( $p$-value < $0.05)$ were entered into the multivariable analysis. In the final model, a significant association was declared at a pvalue of less than 0.05 . And finally, the results were presented in texts and tables with an adjusted odds ratio (AOR) and the corresponding 95\% CI.

\section{Results}

\section{Socio-demographic characteristics}

A total of 397 disabled persons were interviewed with a response rate of $96.4 \%$. The mean age of the respondents was $27.7( \pm 7.1 \mathrm{SD})$ years. Most of the respondents (45.2\%) had impaired mobility. Fifty-six percent of respondents were female and $48.1 \%$ of participants were single. The highest number of study participants were Orthodox Christians (93.0\%). A quarter of participants were living alone and $41.1 \%$ of disabled persons had no job. Regarding the educational level of the respondents, $48 \%$ (48.5\%) of respondents had completed primary education (Table 1).

\section{Knowledge and practice of participants about FP methods}

As indicated in Table 2, about $85 \%$ of disabled persons had ever heard about FP methods. The most common source of information was the media (television/radio (69.1\%). The mean number of FP methods known by respondents was $44.6 \%$. About three-fourth $(74.8 \%)$ of the respondents knew injectable while withdrawal (18.1\%) was the least known traditional FP method. The mean score of side effects reported by participants was $31.5 \%$. Heavy bleeding or irregular bleeding was the most 
Table 1 Sociodemographic characteristics of respondents in North-shewa zone, Ethiopia, 2019

\begin{tabular}{|c|c|c|}
\hline $\begin{array}{l}\text { Socio-demographic } \\
\text { characteristics }(\boldsymbol{N}=397)\end{array}$ & Categories & N (\%) \\
\hline \multirow{5}{*}{$\begin{array}{l}\text { Form of disability of } \\
\text { respondents }\end{array}$} & Partial mental impairment & $13(3.3)$ \\
\hline & Hearing impairment & $57(14.4)$ \\
\hline & Visual impairment & $94(23.7)$ \\
\hline & Impaired mobility & 197(45.2) \\
\hline & Multiple impairments & 53(13.3) \\
\hline \multirow[t]{3}{*}{ Age } & $18-30$ & $271(68.1)$ \\
\hline & $31-40$ & $47(11.9)$ \\
\hline & $41-50$ & $79(20.0)$ \\
\hline \multirow[t]{2}{*}{ Sex } & Female & 173(43.7) \\
\hline & Male & $224(56.3)$ \\
\hline \multirow[t]{3}{*}{ Marital status } & Married & 142(35.9) \\
\hline & Single & 191(48.1) \\
\hline & Divorced/widowed & $64(15.9)$ \\
\hline \multirow[t]{3}{*}{ Religion } & Orthodox & 369(93.0) \\
\hline & Muslim & $19(4.8)$ \\
\hline & Protestant/Catholic & $9(2.3)$ \\
\hline \multirow[t]{4}{*}{ Educational status } & No education & $94(23.7)$ \\
\hline & Primary education & 194(48.9) \\
\hline & Secondary education & $52(13.0)$ \\
\hline & College education & $57(14.4)$ \\
\hline \multirow[t]{5}{*}{ Work status } & Had no job & 163(41.1) \\
\hline & Student & 63(15.9) \\
\hline & Employed & $57(14.4)$ \\
\hline & Lottery seller & $41(10.3)$ \\
\hline & $\begin{array}{l}\text { Others (merchants, daily } \\
\text { laborer, beggar, tailor) }\end{array}$ & 73(18.3) \\
\hline \multirow[t]{5}{*}{ Living condition } & With parents & $105(26.3)$ \\
\hline & With relatives & $21(5.2)$ \\
\hline & With friends/peers & 124(31.4) \\
\hline & With partner & $93(23.5)$ \\
\hline & Alone & $54(13.6)$ \\
\hline
\end{tabular}

reported side effect of modern contraceptives (35.9\%). Overall, $46 \%$ of study participants were knowledgeable about family planning methods. Only a quarter (24.4\%) of disabled persons currently utilized any of family planning methods. Of these family planning users, 76(77.6\%) of them were females (Table 2).

\section{Attitude of participants towards FP methods}

In this study, the calculated mean score of the attitudinal statements was $1.83( \pm 0.39 \mathrm{SD})$. Forty-four percent (44.4\%) of the respondents were above the mean score and they were considered as having a poor attitude towards FP methods (Table 3).
Table 2 The respondents' knowledge and practice of FP methods in North-shewa zone, Ethiopia, 2019

\begin{tabular}{|c|c|c|}
\hline Variables & Categories & \\
\hline \multirow{2}{*}{$\begin{array}{l}\text { Have you ever heard about } \\
\text { FP methods? ( } n=337)\end{array}$} & Yes & $337(84.9)$ \\
\hline & No & $60(15.1)$ \\
\hline \multirow{6}{*}{$\begin{array}{l}\text { What was the source of } \\
\text { information for FP? }(n=337)\end{array}$} & Television/radio & 233(69.1) \\
\hline & School teachers & 134(39.8) \\
\hline & $\begin{array}{l}\text { Health } \\
\text { professionals }\end{array}$ & $196(58.2)$ \\
\hline & Associations & $67(19.8)$ \\
\hline & Training & 116(34.6) \\
\hline & Others $^{a}$ & $99(29.6)$ \\
\hline What is FP $(\mathrm{N}=337)$ & Yes & No \\
\hline Limiting of number of children & $174(51.5)$ & $163(48.5)$ \\
\hline The spacing of birth intervals & 288(85.5) & $44(13.2)$ \\
\hline Stopping births & $85(25.0)$ & $250(74.4)$ \\
\hline
\end{tabular}

Which type of FP methods Yes No

did you know? $(n=337)$

Oral contraceptive pills

212(62.8)

125(37.2)

Condoms

$154(45.6)$

Injectable

$85(25.2)$

Implants

183(54.4)

$146(43.4)$

Intrauterine contraceptive devices

206(61.1)

Sterilization (male and female)

Calendar method

245(72.6)

240(71.2)

Periodic abstinence

205(60.6)

Withdrawal (coitus interruptus)

276(81.9)

Lactational amenorrhea method

Mean number of methods known

What are the side effects of using family planning?

Heavy bleeding or irregular bleeding

Absence of menstrual cycle

Abdominal cramp

$59(17.4)$

278(82.6)

Do not know

148(43.8)

189(56.2)

Mean score of side effects known

106(31.52)

Do you currently utilize any of family planning methods?

Overall FP knowledge level

\section{Not} knowledgeable

182(54.0)

299(75.5)

Knowledgeable

155(46.0)

${ }^{\mathrm{a}}$ Parent, friends, magazine, books

Factors associated with knowledge, attitude, and practice of FP methods

In the bivariate model, the sex of the respondents and level of education were statistically significant with the knowledge of FP methods. Besides, age, marital status, 
Table 3 The respondents' attitude towards FP methods in North-shewa zone, Ethiopia, 2019

\begin{tabular}{|c|c|c|c|}
\hline Variables & Agree & Disagree & Do not know \\
\hline Do you think using FP makes women unhealthy? & 143(35.9) & 187(47.0) & $67(17.0)$ \\
\hline Do you think pregnancy must be properly planned? & 316(79.6) & $37(9.3)$ & $44(11.1)$ \\
\hline Do you think pregnancy spaced $<2$ years should be avoided by using family planning methods? & 214(54.1) & 104(26.3) & 78(19.6) \\
\hline Do you think the use of FP methods interfere sexual relationship between husband and wife? & $88(22.2)$ & 232(58.5) & $77(19.3)$ \\
\hline Do you think using modern FP methods causes anger from God? & 198(50.0) & 150(37.8) & $48(12.2)$ \\
\hline Do you think FP methods result in infertility to get pregnant later on? & 118(29.6) & 194(48.9) & $85(21.5)$ \\
\hline Do you think women are more responsible than men for using modern FP methods? & $131(58.1)$ & 114(28.9) & $52(13.0)$ \\
\hline \multirow[t]{2}{*}{ Overall family planning attitude level } & Poor attitude & \multicolumn{2}{|c|}{ Good attitude } \\
\hline & $176(44.4)$ & \multicolumn{2}{|l|}{$221(55.6)$} \\
\hline
\end{tabular}

and knowledge of FP methods were associated with the utilization of any type of FP methods in the bivariate model. As indicated in Table 4, the results of the multivariate analysis showed that respondents who completed the primary education were three times more likely to have a good knowledge of FP methods than uneducated participants $(\mathrm{AOR}=3.31 ; 95 \% \mathrm{CI}=1.37$, 7.59). Moreover, participants who completed college education were 7 times more likely to have a good knowledge of FP methods than participants who were uneducated (AOR = 7.23; $95 \% \mathrm{CI}=2.28,22.06$ ). Moreover, participants who had a good knowledge of FP methods was 1.6 times $(\mathrm{AOR}=1.61, \mathrm{CI}=1.27,16.24)$ more likely to utilize any type of FP methods than those having poor knowledge of FP methods (Table 4).

\section{Discussions}

This study highlights interesting insights into the knowledge, attitude, and practice of family planning methods among persons with disabilities in North-shewa zone, Amhara regional state, Ethiopia, unfortunately, there is very limited data and unclear understanding of the knowledge has been problematic. The current study reported the level of knowledge, attitude, and practice of family planning methods among disabled persons who are marginalized groups of the populations. Accordingly, $46 \%$ of study participants were knowledgeable about family planning methods. Likewise, the mean number of family planning methods known by respondents was $44.6 \%$. The injectable was the most known method of modern contraception $(74.8 \%)$ while withdrawal (18.1\%)

Table 4 The analyses of factors associated with the knowledge and the current FP methods utilization among respondents in the North-shewa zone, Ethiopia, 2019

\begin{tabular}{|c|c|c|c|c|c|}
\hline \multicolumn{2}{|c|}{$\begin{array}{l}\text { Variables associated with knowledge of FP methods }(n= \\
\text { 337) }\end{array}$} & \multirow{2}{*}{$\begin{array}{l}\text { Poor knowledge } \\
58.4\end{array}$} & \multirow{2}{*}{$\begin{array}{l}\text { Good knowledge } \\
35.6\end{array}$} & \multirow{2}{*}{$\begin{array}{l}\text { COR }(95 \% \mathrm{CI}) \\
1.00\end{array}$} & \multirow{2}{*}{$\begin{array}{l}\text { AOR }(95 \% \mathrm{Cl}) \\
1.00\end{array}$} \\
\hline Sex & Female & & & & \\
\hline & Male & 41.8 & 64.4 & $2.54(1.03,2.77)^{*}$ & $3.12(0.76,8.11)$ \\
\hline \multirow[t]{4}{*}{ Educational status } & No education & 24.6 & 8.7 & 1.00 & 1.00 \\
\hline & Primary education & 46.7 & 54.8 & $3.21(1.45,7.65)$ & $3.31(1.37,7.59)^{*}$ \\
\hline & Secondary education & 18.9 & 11.5 & $1.71(0.63,4.83)$ & $1.83(0.65,5.12)$ \\
\hline & College education & 9.8 & 25.0 & $6.96(2.63,19.85)$ & $7.23(2.28,22.06)^{*}$ \\
\hline \multicolumn{2}{|c|}{$\begin{array}{l}\text { Variables associated with the current FP utilization }(n= \\
\text { 337) }\end{array}$} & Not utilized FP methods & Utilized FP methods & & \\
\hline \multirow[t]{3}{*}{ Age } & $18-30$ & 68.5 & 66.7 & 1.00 & 1.00 \\
\hline & $31-40$ & 10.8 & 15.2 & $1.48(1.02,7.65)^{*}$ & $1.71(0.93,3.91)$ \\
\hline & $41-50$ & 20.7 & 18.1 & $0.91(0.51,1.58)$ & $0.80(0.56,2.13)$ \\
\hline \multirow[t]{3}{*}{ Marital status } & Single & 53.2 & 33.3 & 1.00 & 1.00 \\
\hline & Married & 30.5 & 51.5 & $2.71(1.45,5.00)^{*}$ & $3.41(1.74,6.68)^{*}$ \\
\hline & Divorced/widowed & 16.3 & 15.2 & $1.9(0.64,3.46)$ & $2.11(0.86,5.71)$ \\
\hline \multirow[t]{2}{*}{ Respondent's knowledge on FP } & Poor knowledge & 77.0 & 23.0 & 1.00 & 1.00 \\
\hline & Good knowledge & 68.3 & 31.7 & $1.54(1.11,12.50)^{*}$ & $1.61(1.27,16.24)^{*}$ \\
\hline
\end{tabular}

$1=$ Reference, ${ }^{*} p$-value $<0.05$ 
was the least known traditional FP method. This figure was slightly lower than the study reported in KampalaUganda [23]. Even though the knowledge of contraceptive methods among disabled people was not comparable with the general population, findings from the EDHS data also revealed that disabled people's knowledge on family planning methods was much lower than our result [21]. In Senegal, people with disabilities had very low knowledge about contraception [24]. Women with intellectual disabilities lacked basic knowledge of contraception in Southeast England [25]. This could be due to persons with disabilities commonly have a restricted access to the use of family planning methods, and they are often socially isolated in obtaining FP services.

Although $55 \%$ of our study participants had favorable attitude about modern contraception, only one-fourth (24.5\%) of participants currently utilized any method of contraceptives. In line with our finding, the majority of disabled women had a favorable attitude, but the utilization of FP methods by respondents was poor [2628]. However, our finding was lower than the study conducted in Addis Ababa where 35\% of persons with disabilities utilized modern contraceptives [24]. In Nigeria, $34 \%$ of physically disabled adolescents utilized modern contraceptive methods [29]. The utilization of FP methods was 39\% among people with disabilities in Kampala district, Uganda [23]. This difference is probably because disabled people are discouraged from discussing sexual-related issues in the study area due to some cultural influences.

In the multivariate analysis, participants who had a good knowledge of FP methods were more likely to utilize any type of FP methods than those having poor knowledge. This agreed with a study reported by $\mathrm{E}$ Smith et al. [30] where awareness of family planning determined the utilization of modern contraception. Moreover, participants who completed college education were 7 times more likely to have a good knowledge of FP methods than none-educated participants. Similarly, lower education level was associated with lower utilization of family planning among disabilities [27, 28]. This is plausible finding in that education is a foundation for utilization of FP methods among disabled people through developing their knowledge. Moreover, our finding suggested that knowledge of FP have a positive impact on the utilization of FP methods among disabled people. It could be also explained that as the level of education increased, the person's level of seeking health information also increased which again improves the practice of FP utilization and services.

Despite its strengths, this study has some limitations that must be acknowledged. Although our study had a diverse set of participants, the study focused on disability-support organizations that may miss some people with disabilities in the community. The authors also acknowledge the possibility of information bias created by the sign language interpreters to interpret for respondents who had a hearing impairment, and the limitations associated with self-reported data.

\section{Conclusions}

In this study, the knowledge, attitude, and practice of disabled people about FP methods were relatively low. Due attention should be given to ensure that disabled people are well informed about FP methods through information, education and communication activities.

\section{Abbreviations \\ AOR: Adjusted Odds Ratio; Cl: Confidence Interval; COR: Crude Odds Ratio; FP: Family Planning; SD: Standard Deviation; SPSS: Statistical Package for the Social Sciences; SRH: Sexual and Reproductive Health}

\section{Acknowledgements}

We would like to thank Debre Berhan University for financial grants to carry out this study. We are grateful to Debre Berhan zone social affairs office for providing us disability-related data. We would also like to acknowledge our study participants, data collectors, and district social experts who kindly participated in this study.

\section{Authors' contributions}

$A G, A D, Y A, T D, M A^{5}$ and $M A^{6}$ participated in the design of the study, supervised the data collection. AG analyzed and interpreted the data, drafted and edited the manuscript. All authors read and approved the final manuscript.

\section{Funding}

This study was funded by grant support from Debre Berhan University (protocol No: RCSVP/10073//07/2018) in Ethiopia. The funding university did not have any role in the design of the study, data collection, analysis and interpretation of data, and in writing the manuscript.

\section{Availability of data and materials}

All data generated/analyzed during this study are included in this published article. Besides, part of the row datasets will be available from the corresponding author on a reasonable request.

\section{Ethics approval and consent to participate}

Ethical approval was obtained from the research and an ethical review committee of Debre Berhan University. Written informed consent was obtained from each study participant. All the information obtained from the study participants were kept confidential throughout the process of study, and the name of the participant was replaced by code. Withdrawal from the study at any point if they wished was assured.

\section{Consent for publication}

Not applicable.

\section{Competing interests}

The authors declare that they have no competing interests.

\section{Author details}

1 Department of Nursing, College of Health Science, Debre Berhan University, Po. Box 445, Debre Berhan, Ethiopia. ${ }^{2}$ Department of Midwifery, College of Health Science, Debre Berhan University, Po. Box 445, Debre Berhan, Ethiopia. ${ }^{3}$ Department of Medical Laboratory, College of Medicine, Debre Berhan University, Po. Box 445, Debre Berhan, Ethiopia. 
Received: 18 March 2020 Accepted: 15 June 2020

Published online: 01 July 2020

\section{References}

1. Eliason S, Awoonor-Williams JK, Eliason C, Novignon J, Nonvignon J, Aikins M. Determinants of modern family planning use among women of reproductive age in the Nkwanta district of Ghana: a case-control study. Reprod Health. 2014;11(1):65

2. Kasa AS, Tarekegn M, Embiale N. Knowledge, attitude and practice towards family planning among reproductive-age women in resource-limited settings of Northwest Ethiopia. BMC Res Notes. 2018;11(1):1-6.

3. Takele A, Degu G, Yitayal M. Demand for long-acting and permanent methods of contraceptives and factors for non-use among married women of Goba town, bale zone, South East Ethiopia. BMC Reprod Health. 2012; 9(1):26.

4. Choi Y, Fabic MS, Hounton S, Koroma D. Meeting demand for family planning within a generation: prospects and implications at country level. Glob Health Action. 2015;8(1):29734

5. Gonie A, Wudneh A, Nigatu D, Dendir Z. Determinants of family planning use among married women in bale eco-region, Southeast Ethiopia: a community-based study. BMC Womens Health. 2018;18(1):50.

6. Family Planning 2020 Country Action: Opportunities, Challenges, and Priorities in Ethiopia. https://www.familyplanning2020.org/sites/default/files/ Country_Action_Opportunities-Challenges-and-Priorities_ETHIOPIA_FINAL. pdf. Accessed 15 Mar 2020

7. Tilahun $\mathrm{T}$, Coene $\mathrm{G}$, Luchters $\mathrm{S}$, Kassahun W, Leye $\mathrm{E}$, Temmerman M, Degomme O. Family planning knowledge, attitude and practice among married couples in Jimma Zone, Ethiopia. PLoS One. 2013;8(4):1-7.

8. Fabic MS, Choi Y, Bongaarts J, Darroch JE, Ross JA, Stover J, Tsui AO, Upadhyay J, Starbird E. Meeting demand for family planning within a generation: the post-2015 agenda. Lancet. 2015;385(9981):1928-31.

9. Obasi M, Manortey S, Kyei KA, Addo MK, Talboys S, Gay L, Baiden F. Sexual and reproductive health of adolescents in schools for people with disabilities. Pan Afr Med J. 2019;33:299.

10. Shakespeare T, lezzoni LI, Groce NE. Disability and the training of health professionals. Lancet. 2009;374(9704):1815-6.

11. Tanabe M, Nagujjah Y, Rimal N, Bukania F, Krause S. Intersecting sexual and reproductive health and disability in humanitarian settings: risks, needs, and capacities of refugees with disabilities in Kenya, Nepal, and Uganda. Sex Disabil. 2015;33(4):411-27.

12. Kassa TA, Luck T, Bekele A, Riedel-Heller SG. Sexual and reproductive health of young people with disabilities in Ethiopia: a study on knowledge, attitude, and practice: a cross-sectional study. Glob Health. 2016;12(1):5.

13. Milligan MS, Neufeldt AH. The myth of asexuality: a survey of social and empirical evidence. Sex Disabil. 2001;19(2):91-109.

14. Mprah WK. Knowledge and use of contraceptive methods amongst deaf people in Ghana. Afr J Disabil. 2013;2(1):43.

15. Anderson P, Kitchin R. Disability, space and sexuality: access to family planning services. Soc Sci Med. 2000;51(8):1163-73.

16. Devkota HR, Murray E, Kett M, Groce N. Healthcare provider's attitude towards disability and experience of women with disabilities in the use of maternal healthcare service in rural Nepal. Reprod Health. 2017;14(1):79.

17. Promoting sexual and reproductive health for persons with disabilities WHO/UNFPA guidance note. 2009. https://apps.who.int/iris/bitstream/ handle/10665/44207/9789241598682_eng.pdf. Accessed 15 Mar 2020.

18. Abdul KA. Exploring the sexual and reproductive health issues of visually impaired women in Ghana. Reprod Health Matters. 2017;25(50):128-33.

19. Fraser E, Corby N. Family Planning for women and girls with disabilities, Disability Inclusion Helpdesk Research Report No. 2 (pilot). London: Disability Inclusion Helpdesk; 2019.

20. Eide AH, Mannan H, Khogali M, Van Rooy G, Swartz L, Munthali A, Hem KG, MacLachlan M, Dyrstad K. Perceived barriers for accessing health services among individuals with a disability in four African countries. PLoS One. 2015;10(5):e0125915. https://doi.org/10.1371/journal.pone.0125915.

21. Central Statistical Agency (CSA) [Ethiopia] and ICF. Ethiopia Demographic and Health Survey 2016. Addis Ababa, Ethiopia, and Rockville: CSA and ICF 2016.

22. Van Schrojenstein Lantman-de Valk HM, Rook F, Maaskant MA. The use of contraception by women with intellectual disabilities. J Intellect Disabil Res. 2011;55(4):434-40
23. Mulindwa IN. Study on reproductive health and HIV/AIDS among persons with disabilities in Kampala, Katakwi and Rakai districts. Kampala: Disabled Women's Network and Resource Organization; 2003. https://asksource.info/ resources/study-reproductive-health-and-hivaids-among-persons-disabilitieskampala-katakwi-and-rakai.

24. Kassa TA, Luck T, Birru SK, Riedel-Heller SG. Sexuality and sexual reproductive health of disabled young people in Ethiopia. Sex Transm Dis. 2014:41(10):583-8.

25. McCarthy M. Contraception and women with intellectual disabilities. J Appl Res Intellect Disabil. 2009;22(4):363-9.

26. Gürel R, YIlmaz DV. Examining the attitude towards family Planning of women with disability in Turkey. Sex Disabil. 2018;36(3):265-75.

27. DeBeaudrap $P$, Mouté $C$, Pasquier E, Mac-Seing M, Mukangwije PU, Beninguisse G. Disability and access to sexual and reproductive health services in Cameroon: a mediation analysis of the role of socioeconomic factors. Int J Environ Res Public Health. 2019;16(3):417.

28. Ngilangwa DP, Rajesh S, Kawala M, Mbeba R, Sambili B, Mkuwa S, Noronha R, Meremo AJ, Nyagero J. Accessibility to sexual and reproductive health and rights education among marginalized youth in selected districts of Tanzania. Pan Afr Med J. 2016;25(2):1-7.

29. Olajide FO, Omisore AG, Arije OO, Afolabi OT, Olajide AO. Awareness and use of modern contraceptives among physically challenged in-school adolescents in Osun state, Nigeria. Afr J Reprod Health. 2014;18(2):87-96.

30. Smith E, Murray SF, Yousafzai AK, Kasonka L. Barriers to accessing safe motherhood and reproductive health services: the situation of women with disabilities in Lusaka. Zambia Disabil Rehabil. 2004;26(2):121-7.

\section{Publisher's Note}

Springer Nature remains neutral with regard to jurisdictional claims in published maps and institutional affiliations.

Ready to submit your research? Choose BMC and benefit from:

- fast, convenient online submission

- thorough peer review by experienced researchers in your field

- rapid publication on acceptance

- support for research data, including large and complex data types

- gold Open Access which fosters wider collaboration and increased citations

- maximum visibility for your research: over $100 \mathrm{M}$ website views per year

At BMC, research is always in progress.

Learn more biomedcentral.com/submissions 